\title{
A formação de professores em grupos de estudos e pesquisas pelo conviver espontâneo
}

Teacher training in study groups and researches on spontaneous living together

\author{
D. T. A. Aseff ${ }^{1 *}$; S. C. Rodrigues ${ }^{1}$ \\ ${ }^{1}$ Programa de Pós-Graduação em Educação em Ciências/Universidade Federal do Rio Grande-FURG, CEP: \\ 96203-900, Rio Grande-RS-Brasil \\ *di.aragon@hotmail.com \\ (Recebido em 07 de agosto de 2017; aceito em 29 de janeiro de 2018)
}

\begin{abstract}
Este estudo propõe uma reflexão acerca dos grupos de estudos e pesquisas que acolhem professores da educação básica, professores universitários e acadêmicos dos cursos de licenciatura de uma universidade pública federal do extremo sul do Brasil. A pesquisa narrativa foi a escolha metodológica por acolher a experiência e, com isso, deixar emergir explicações sobre o fenômeno. Nessa direção, investigou-se como o linguajar e o emocionar que permeiam esses grupos de estudos e pesquisas proliferam potencialidades na formação de professores, assim, mantendo-os ativos no conviver espontâneo. Apresenta-se, aqui, a temática que demarcou confluências às narrativas e, a partir dessa, foram problematizadas as relações que se individuaram em rede e demarcaram, nesta investigação, a experiência como acontecimento. $\mathrm{O}$ estudo, por fim, assume que a convivência em grupos de estudos e pesquisas prolifera potencialidades na formação de professores pela possibilidade do encontro com a experiência que transforma os sujeitos.

Palavras-chave: formação de professores, conviver espontâneo, experiência.
\end{abstract}

This study proposes a reflection on study groups and researches that welcome basic education teachers, university professors and undergraduate students from a public federal university in the extreme south of Brazil. The narrative research was a methodological choice for it welcomes this experience and thus lets an explanation on this phenomenon emerge. In this sense, we investigate how the language and emotions that permeate these study groups and researches can increase potentialities in teacher training and keep them active in the spontaneous living together. We present the thematic that demarcated confluences among the narratives and, from this, we problematize the relations that occur in a network and that delimit, in this investigation, the experience as a happening. We conclude the study assuming that the living together in study groups and researches proliferates the potentialities by the possibility of the encounter with the experience that transforms the people.

Keywords: Teacher training, spontaneous living together, experience

\section{INTRODUÇÃO}

Este artigo apresenta resultados de uma pesquisa realizada em uma universidade federal, situada no extremo sul do Brasil, que propõe uma reflexão acerca dos grupos de estudos e pesquisas que acolhem professores da educação básica, professores universitários e acadêmicos dos cursos de licenciatura para conhecer o que mantém esses grupos ativos.

Um Grupo de Pesquisa (GP) é definido, pelo Conselho Nacional de Desenvolvimento Científico e Tecnológico (CNPq), como um conjunto de indivíduos organizados em torno de um ou mais objetos de estudo. A liderança do grupo deve ser exercida por um pesquisador, com titulação preferencialmente de doutor. A constituição do grupo é dada pela existência de um ou mais docente(s) pesquisador(es), um ou mais estudante(s) de graduação, de pós-graduação ou técnico(s) de nível superior. O GP deverá evidenciar que há envolvimento permanente com atividades de pesquisa e que o trabalho se organiza em torno de linhas comuns de pesquisa [1].

A partir dessa definição, buscamos por investigações envolvendo a formação de professores em grupos de estudos e pesquisas que integram professores, mapeadas no banco de dados da Comissão de Aperfeiçoamento de Pessoal do Nível Superior (CAPES), assim como em artigos presentes no acervo digital da Scientific Electronic Library Online (SciELO), inseridos na mesma temática. $\mathrm{O}$ estudo e reconhecimento das produções acadêmicas já existentes, repertoriado no 
período de 2006 a 2016, permitiram situar a pesquisa supracitada e alcançar resultados, explicações e argumentos que demarcam a originalidade desta. A intencionalidade da busca pelas produções já existentes foi conhecer se havia trabalhos de grupos que integrassem professores universitários, professores da educação básica e acadêmicos de cursos de licenciaturas. Com esse critério, as pesquisas de Marchi (2011) [2] e Orfão (2012) [3] foram as selecionadas para integrar o estudo, a partir das buscas no banco de dados da CAPES. A busca no acervo digital SciELO seguiu o mesmo critério e individuou as produções de Loponte (2009) [4] e Gabardo e Hagemeyaer (2010) [5].

Nas pesquisas de Marchi (2011) [2], Órfão (2012) [3], Gabardo e Hagemeyaer (2010) [5] e Loponte (2009) [4], foi possível capturar alguns resultados e, a partir deles, identificar aproximações e fazer distinções entre esses e a pesquisa que ora é apresentada. Um tema de aproximação encontrado nas pesquisas mapeadas foi a discussão que os grupos proporcionaram pertinente aos conhecimentos do professor.

No mapeamento, não pretendíamos justapor informações nem as sintetizar, mas compor um elemento implicado num trabalho de seleção e estudo, considerando o que já está posto e dito no campo por nós investigado. Entendemos que, ao reunir as discussões sobre resultados de pesquisas anteriores, é possível vislumbrar contribuições nesse campo de estudo e, a partir dessas reflexões, orientar caminhos para a pesquisa que problematiza a formação de professores em grupos de estudo.

Os trabalhos supracitados indicam que os grupos são espaços de profissionalização por oportunizarem uma formação proveniente das experiências vividas pelo trabalho colaborativo. Desse modo, evidencia-se a importância do processo contínuo de aprendizagem na docência, no sentido de que o professor possa, além de responsabilizar-se pela própria ação, dinamizar e conhecer seus modos de aprender para, assim, pensar e problematizar as diferentes maneiras de como o outro aprende; e, mediante essas ações, construir um modo singular e ético de ser professor. Nessa perspectiva, os grupos de professores que se encontram para discutir, refletir e pensar conteúdos amalgamam características singulares por possibilitarem o estudo e a formação entrelaçados aos saberes que são compartilhados e, por vezes, ressignificados.

Participar de um grupo de estudos, ou de pesquisa, tem que ver com estar atravessado pela experiência, proposto por Larrosa $(2015$, p.18) [6], no sentido do "que nos passa, o que nos acontece, o que nos toca. Não o que se passa, não o que acontece, ou o que toca". Assim, participar é diferente de estar presente no grupo ou conhecer algo que não sabíamos. Conhecimento e saberes diferem-se de informações; e estar, sentir e fazer a docência passam pelo estar, sentir e dar sentido ao que aprendemos e ensinamos. Ao conhecer os trabalhos que fazem parte da literatura existente acerca da temática, entendemos que a formação de professores em grupos de estudos e pesquisas se mostra como um campo profícuo de investigação e, com isso, inspira outras pesquisas a fim de ampliar as reflexões e discussões no tocante a essa temática. Nesse sentido, propusemo-nos a realizar uma investigação sobre "a formação de professores em grupos de estudos e pesquisas" em diferentes campi de uma universidade pública federal localizada no extremo sul do país.

O foco da pesquisa centrou-se no "linguajar" e no "emocionar" que permeiam as propostas dos grupos de estudos e pesquisas, que acolhem, pelo conviver espontâneo, os professores universitários, professores da educação básica e acadêmicos em formação inicial dessa universidade. O termo "linguajar" é utilizado por Maturana (2009) [7] para reconceituar a noção de linguagem, "enfatizando seu caráter de atividade, de comportamento e, evitando assim a associação como uma 'faculdade' própria da espécie, como tradicionalmente se faz" (p.21) [7]. O "emocionar" está relacionado com "o fluir de uma emoção a outra, é o fluir de um domínio de ações a outro" (p.203)[8]. Desse modo, o autor convida-nos a reconhecer que "as emoções são disposições corporais que especificam domínios de ações, e que as diferentes emoções se distinguem precisamente porque especificam domínios de ações distintos" (p.203) [8]. Diante dessa outra cultura de formação, que propõe espaços de convivências, pautados pela espontaneidade do encontro com o outro, em que momentos de estudos são permeados pela cooperação e acolhimento, visualizamos as interações mobilizadas pelo emocionar do diálogo e do respeito. 
Essas constatações inspiraram esta investigação e possibilitaram-nos capturar elementos e tecer explicações sobre como os grupos de estudos que realizam ações vinculadas à educação integram professores universitários, professores da educação básica e acadêmicos dos cursos de licenciatura e mobilizam-nos para encontros espontâneos de formação.

\section{MATERIAL E MÉTODOS}

Na sequência, apresentamos a problematização do estudo, os grupos colaboradores da investigação e o aporte metodológico que possibilitou analisar as narrativas dos coordenadores.

\subsection{A problematização do estudo}

Na pesquisa, problematizamos o estudo mediante a seguinte pergunta: como o linguajar e o emocionar que permeiam os espaços de formação inicial e continuada nos grupos de estudos e pesquisas integram, pelo conviver espontâneo, professores universitários, professores da educação básica e acadêmicos de cursos de licenciatura?

A intenção foi de que as explicações geradas trouxessem subsídios para pensar, propor ou mesmo ampliar os espaços formativos na formação inicial e continuada de professores.

\subsection{A narrativa como escolha metodológica}

Explicar é o que nos propusemos neste trabalho. Mas o que define o fenômeno a explicar? Para explicar qualquer coisa, traremos elementos da experiência como fenômeno a explicar. De acordo com Maturana (2001, p. 55) [9], "se você faz tal e tal coisa, isto é o que vê, o que mede, o que observa.". De modo que não é o fenômeno, todavia o que o observador tem como experiência que se constitui no que se quer explicar. Acrescenta ainda que as explicações científicas são "proposições de mecanismos gerativos que dão origem como uma consequência ou resultado de sua operação às experiências (aos fenômenos) a serem explicadas" (p. 137) [9]. Nessa ação, não precisamos de um mundo de objetos para fazer as explicações, mas do domínio das experiências do observador.

Assim, os argumentos da pesquisa foram construídos a partir do viver, na própria experiência de construí-los, e não como um observador que se diz independente do processo de construção da explicação. A experiência, neste trabalho, é tratada como algo que nos toca e acontece no fluxo do viver [6].

Ao assumir esse caminho metodológico, o uso de narrativas ganhou sentido e assumiu a perspectiva teórica que embasou a escrita das explicações. A escolha por essa metodologia está relacionada ao reconhecimento do método em três potencialidades: como processo de investigação em educação, como processo de reflexão pedagógica e como processo de formação - ilustradas com episódios relatados por professores [10].

Ademais, o uso de narrativas para olhar os grupos de estudos e pesquisas deve-se aos elementos que poderão ser fundamentados pela experiência a partir das ideias de Clandinin e Connelly (2015) [11] e Jorge Larrosa $(2011,2015)$ [13, 6].

Ao afirmar que a experiência assume um papel de reconstrução, Clandinin e Connelly (2015) [11] tratam dos espaços tridimensionais que envolvem um trabalho de investigação narrativa. Essa reconstrução está relacionada à ação de confrontarmo-nos com o passado, o presente e o futuro. No caso, o narrador conta histórias lembradas dele mesmo, sobre épocas passadas, assim como atuais, e todas essas histórias fornecem roteiros possíveis para o futuro [11].

Ao entrar no campo da pesquisa narrativa, percebemo-nos caminhando por entre as histórias, no lugar definido, por Clandinin e Connelly (2015) [11], como entremeio. O entremeio é esse lugar, talvez, do pensamento, da escrita, das reflexões, das experiências que queremos contar e recontar. Sobre isso, os autores afirmam que, enquanto trabalhamos no espaço tridimensional da pesquisa narrativa, aprendemos a olhar para nós mesmos como sempre no entremeio - localizado em algum lugar ao longo das dimensões do tempo, do espaço, do pessoal e do social. 
A experiência narrada pelo sujeito é sempre singular, permeada por reflexões que propiciam emergir o que lhe aconteceu, tocou, marcou e transformou. Assim, a experiência precisa ser tratada de um modo afinado com a sensibilidade e o cuidado para ganhar uma aproximação do que Larrosa (2011) [12] chama de acontecimento, e, desse modo, proliferar sentidos para a pesquisa e para a formação de professores.

Por esse caminho, propusemo-nos conhecer, pensar, problematizar e analisar o linguajar e o emocionar que permeiam as propostas dos grupos de estudos e pesquisa participantes desta investigação, em que as narrativas, como instrumental educativo, possibilitaram a construção e a desconstrução das experiências dos envolvidos. Defendemos a ideia de que as narrativas provocam transformações na forma como as pessoas compreendem a si próprias e aos outros, pois, ao narrar, outras experiências entrelaçam-se à experiência narrada mediante a reflexão.

Larrosa (1994, p.48) [13] assevera que "o sentido do que somos depende das histórias que contamos e das que contamos a nós mesmos [...], em particular das construções narrativas nas quais cada um de nós é, ao mesmo tempo, o autor, o narrador e o personagem principal". Ao narrar, os sujeitos posicionam-se em relação a uma verdade sobre si, à qual eles mesmos devem contribuir ativamente para produzir.

Essas premissas dão suporte à análise, tendo as narrativas como fontes que atribuem qualificação e integram investigação e formação no mesmo processo, tratado por Larrosa (1994, 2011) $[13,12]$ como processo de subjetivação. O aspecto formativo, presente nas narrativas, prolifera os diferentes mundos por meio das palavras escritas ou ditas pelo narrador.

Para Maturana e Varela (2011) [14], vivemos no mundo e, por isso, fazemos parte dele, compartilhando com outros seres vivos o processo vital, construindo o mundo em que vivemos ao longo de nossas vidas, na ontogenia do ser que, por sua vez, também, constrói-nos no decorrer do caminhar. Os autores mostram que o mundo não está a priori e que o construímos ao longo de nossa interação.

Neste sentido, a pesquisa qualitativa desprende-se da intenção precípua de fazer uma intervenção num espaço de formação e abre possibilidades para que pesquisador e colaboradores organizem suas ideias para o relato, quer escrito, quer oral, de modo a reconstruir sua experiência pela reflexão.

Nessa experiência com o uso de narrativas na pesquisa, estivemos atentos ao que emergiu como oportunidade singular de entendermos o narrar dos colaboradores, com a disposição investigativa que abre para transformar e acolher outros modos de pensar e atuar na formação de professores.

\subsection{Os colaboradores do estudo}

Como a intenção era conhecer grupos que desenvolvessem ações de estudos e pesquisas vinculadas à educação e que integrassem professores universitários, professores da educação básica e acadêmicos dos cursos de licenciatura, convidamos os grupos que atendiam ao nosso critério.

Assim, foram colaboradores do estudo dois professores da universidade que exercem a função de coordenadores desses grupos, que são os criadores e os mediadores dos projetos, orientam o trabalho envolvendo a formação de professores, bem como propõem e acolhem pautas para estudos, planejamentos e produções escritas nos encontros coletivos.

$\mathrm{Na}$ convivência com esses coordenadores, em atividades desenvolvidas na universidade e ao participar dos seminários de um desses grupos, foi possível identificar o entrelaçamento que esses professores (coordenadores) estabelecem com a universidade e a escola pela via dos trabalhos que realizam nos grupos de estudos e pesquisas. Esse elo é constituído pelas ações contínuas desses coordenadores, presentes nos planejamentos e nas experiências vividas por eles. Por isso, entendemos que as vozes dos professores coordenadores foram expressivas para este trabalho de pesquisa.

A seguir, apresentamos os grupos de estudos e pesquisas que configuraram a fonte para conhecer, nesta investigação, as relações entre a teoria e a realidade que vêm constituindo-se na universidade. O Grupo 1 é composto por dezesseis professores universitários, dois professores da 
educação básica e vinte e um acadêmicos; e o Grupo 2 acolhe atualmente quatro professores universitários, quatorze professores da educação básica e vinte e oito acadêmicos.

Para ampliar as informações sobre os espaços que compuseram o campo empírico da investigação, apresentamos algumas características que constituem a identidade de cada grupo e os respectivos objetivos, orientadores da trajetória que demarca os encontros e as produções dos referidos grupos. Esses registros constam nos projetos que originaram os respectivos grupos e que foram compartilhados com a pesquisadora por meio de e-mails enviados pelos coordenadores.

O trabalho desenvolvido pelo Grupo de Estudos 1 repercute diretamente sobre o ensino e a formação de professores à medida que se propõe a desenvolver projetos que envolvem a educação básica e superior, seja fomentando discussões teórico-práticas, com alunos e professores da universidade, seja em projetos direcionados à formação continuada de professores atuantes na educação básica. Além disso, os integrantes do grupo participam de eventos e produzem publicações para a socialização dos resultados com a comunidade acadêmica.

Por sua vez, o objetivo que permeia os trabalhos do Grupo de Estudos 2 volta-se para tornar mais visível o contexto local e global, assim como estabelecer vínculos com as comunidades escolares envolvidas nas ações educativas de licenciandos/as, favorecendo o processo de formação e atuação profissional interdisciplinar, tendo o corpo e o ambiente socioambiental como foco.

\subsection{Operacionalizando o conversar}

Neste trabalho nos propusemos explicar as relações que emergem dos espaços que agregam, ao mesmo tempo, investigação e formação. Os procedimentos éticos da pesquisa estão sustentados pela aprovação da mesma a partir do comitê de ética da Universidade Federal do Rio Grande, sob o Parecer de $n^{\circ}$. 62/2016, que está cadastrado pelo $n^{\circ} .59630516400005324$ na Plataforma Brasil. Após aceite dos participantes, estes foram informados dos objetivos e procedimentos do estudo, sendo-lhes garantido o anonimato em sua colaboração e a confidencialidade de suas respostas. Ademais, solicitou-se aos participantes que assinassem um Termo de Consentimento Livre e Esclarecido (TCLE), de acordo com a "Resolução n. ${ }^{\circ}$ 266/12 sobre Pesquisa Envolvendo Seres Humanos".

Para ter acesso às narrativas sobre as experiências na formação de professores em grupos de estudos e pesquisa, foi realizado um contato inicial com dois coordenadores, por meio de e-mails, então, convidando-os a fazer parte do estudo. O passo seguinte foi realizar um encontro pessoal e individual, agendado para conversar sobre as experiências vividas no grupo de estudos e pesquisas.

Larrosa (p. 28, grifos do autor) [15] refere que "[...] a experiência não é o caminho até um objetivo previsto, até uma meta que se conhece de antemão, mas é uma abertura para o desconhecido, para o que não se pode antecipar nem 'pré-ver' nem 'pré-dizer'”. A partir desse entendimento, organizamos os encontros do seguinte modo: no primeiro instante, foram apresentados ao colaborador os objetivos da pesquisa e, logo após, foi solicitado que este contasse a sua experiência sobre a escolha por essa modalidade de formação, o movimento do grupo desde a sua constituição, os meios de divulgação ou convites, a organização, os planejamentos, a manutenção e a tomada de decisões para reformular as propostas. Essas ações possibilitaram o início do conversar porque, na sequência, deixamo-los livres para contar, lembrar o que os tocou, marcou e transformou na caminhada junto aos grupos de estudos e pesquisas. No tempo em que o coordenador contou sua história, evitamos fazer qualquer interferência para que, desse modo, fosse possível a experiência emergir dessa narrativa.

Em cada etapa desse conversar, foi possível capturar o narrar do sentido que esse trabalho prolifera, compreendido, nesta pesquisa, como o linguajar e o emocionar que mantém esse grupo ativo no tempo presente. A conversa foi gravada em áudio e, após, transcrita para o procedimento de análise e discussão.

Durante os encontros, assumimos o conversar proposto por Maturana (2009) [7] no sentido de "dar voltas com", oriundo de suas raízes do latim. O autor (2009, p. 84) [7] afirma que "a tarefa democrática é gerar um conversar no qual o limite da aceitação seja tão amplo que nos envolva a 
todos num projeto comum, como um desejo básico de convivência que é nosso âmbito de liberdade e nossa referência para nosso agir com responsabilidade social".

Inspirados no campo teórico proposto pelo autor, articulamos um conversar que se configurou no mecanismo de interação para realizar a investigação. O conversar trouxe a possibilidade de, mediante o linguajar, darmos voltas com os coordenadores a fim de compreendermos o fenômeno a ser explicado cientificamente. Nessa proposição, entrelaçamos a convivência para realizar a investigação num processo colaborativo com os coordenadores que aceitaram o convite e que lideram os grupos permeados pelo critério desta pesquisa.

\section{RESULTADOS E DISCUSSÃO}

No conversar, a temática sobre a aproximação entre os grupos de estudos e pesquisas e as escolas da rede de ensino foi recorrente nas narrativas dos coordenadores. Por isso, neste trabalho, discutimos o emocionar presente nessas narrativas que evidenciam as potencialidades, na formação de professores e na transformação do sujeito, vinculadas ao fazer da escola.

A análise das narrativas possibilitou-nos compreender seus significados e teorizá-los em meio à sensibilidade e ao reconhecimento de que é possível um grupo de estudos e pesquisas manterse ativo, como um espaço de formação de professores, com possibilidades para o acontecimento da experiência. Nas vozes dos coordenadores, encontramos a experiência que retrata o elo construído entre a universidade e a escola a partir da vivência no grupo de estudos e pesquisas.

Ao conhecer os caminhos metodológicos propostos nesses espaços de formação, foi possível vislumbrarmos sentimento de acolhimento e valorização da convivência entre os professores da universidade, professores da educação básica e acadêmicos no sentido de disponibilidade para compartilhar conhecimentos no grupo e conversar sobre as leituras e os temas propostos em cada etapa. Esses encontros podem ser considerados como reencontros, que acontecem pela via da pesquisa e proliferam na convivência, em meio às ações da docência universitária, dos estágios de docência e das aproximações espontâneas entre os professores das escolas e da universidade. Para tal, amparamo-nos nas ideias de Maturana [8] sobre cultura e sistemas sociais e em Larrosa [12,6] pelo conceito de experiência.

A seguir, apresentamos as narrativas que tratam da aproximação entre a universidade e a escola pela via dos grupos de estudos e pesquisas, seguidas da discussão.

Então, veja como é que a gente chega nos professores, a gente chega, na verdade, porque os nossos objetos de pesquisa envolvem escola, né. A gente não tem objetos "duros". Pelo menos nós, que estamos desde o começo, né, talvez, inclusive, outros colegas que chegaram depois, não tinham objetos que articulavam a escola. Os objetos eram mais teóricos ou de uma linguística mais cultural, vamos dizer assim, e chegaram na escola porque acabaram atuando em estágio e se envolveram também. Acho que o GELC teve um papel aí. Eu não vejo o GELC com a ênfase nessa relação dos professores com a escola, a ênfase de fato, quem constrói, quem está ali na liderança e construindo são os professores da universidade, e aí os professores da escola entram nessa relação, como eu te disse, que eu acho que é uma relação de rede mesmo. Há um professor que tem um interesse em estudar os temas que são trabalhados e que refletem nos planejamentos dos estagiários, um professor que tem o interesse num mestrado ou numa especialização. (...) a gente não consegue mais pensar sem os professores da escola, eles que entraram no grupo para estudos e formações, se inspiraram em fazer a especialização, agora uns mestrandos outros já mestres. Porque são com os mestrandos que a gente tem que pensar, são eles que estão construindo essas propostas no momento. Então, isso agora é orgânico, e o grupo ganha uma Identidade forte na pesquisa. 
Nossas perspectivas, agora, se voltam para o aprofundamento do envolvimento com as comunidades escolares em direção ao estudo das diferentes realidades socioambientais, agregando os materiais elaborados nestes anos, elaborando o mapa socioambiental a ser distribuído como material pedagógico aos professores e às professoras. Trabalho tanto mais rico quanto maior for nossa capacidade de aproximação com as instituições escolares. $O$ trabalho, portanto, se encaminhou em direção às comunidades escolares, a partir do convite da $10^{a}$ CRE, e para o alargamento da visão sobre a região de Uruguaiana, para seus múltiplos aspectos; ou seja, ao mesmo tempo em que buscamos associar estudo de realidades com propostas pedagógicas, criamos oportunidades para estudantes se aventurarem em espaços, lugares, ritmos e ambientes não urbanizados, nas histórias esquecidas ou apagadas.

Quadro 2: Narrativa do Coordenador 2

Em suas narrativas, os coordenadores evidenciam que os professores da universidade e os professores das escolas que participam dos grupos são os protagonistas das relações que se dão nessas redes, e que as pesquisas que envolvem a escola são frutos das escolhas teóricas dos professores universitários e dos acadêmicos, advindos, principalmente, dos temas de trabalhos de conclusões de cursos de graduação e de pós-graduação e dos escritos desenvolvidos no período de estágio de docência. Essas produções enlaçam-se às práticas da docência, imersas nas realidades escolares, e, com isso, integram professores universitários, acadêmicos e professores da educação básica, originando ações e relações profissionais. Compreender essas redes, assim como o linguajar e o emocionar que permeiam essas relações, foi o objetivo do estudo.

Amparados nos aportes teóricos da Biologia do Conhecer, entendemos que os grupos de estudos e pesquisas são um sistema social e como tal incorporam a "conservação da vida de seus membros como parte de sua definição operatória como sistema" (p. 239) [8], o que nos leva a supor que esses se mantêm ativos há alguns anos porque conservam seus modos de viver. Para o autor [8], um sistema social é composto pelos:

[...] membros de um conjunto de seres vivos que constituem, com sua conduta, uma rede de interações que opera para eles como um meio no qual eles se realizam como seres vivos, e no qual eles, portanto, conservam sua organização e adaptação, e existem em uma co-deriva contingente com sua participação em tal rede de interações. (p. 238).

O Grupo 1 está ativo desde o ano de 2009; e o Grupo 2, desde 2011. Em suas narrativas, os coordenadores relatam o empenho de todos em conservar a vida docente no grupo e o envolvimento de seus integrantes nas ações propostas, assim como intensificar esse envolvimento a cada etapa. Suas falas reverberam que a aproximação entre a universidade e a escola é o que enriquece o trabalho de estudos e pesquisas desenvolvido no grupo e fortalece a continuidade do grupo. Nesse caminhar, voltam-se para o envolvimento com as comunidades escolares, em direção ao estudo das diferentes realidades, e consideram que o trabalho é tanto mais rico, quanto maior for essa capacidade de aproximação com as instituições escolares.

Nas pesquisas de Marchi [2], Órfão [3], Gabardo e Hagemeyaer [5] e Loponte [4], o processo de reflexão do conhecer, também, ocorreu e surgiu na linguagem, ou seja, quando as pessoas envolvidas colocaram-se no conversar, dando voltas com o outro, para conhecer o outro e compartilhar conhecimentos. E, ainda, evidenciaram que os contextos de formação de professores em grupos de trabalho revelam espaços favoráveis para o estudo e planejamento dos afazeres docentes, pelas formas de compartilhar saberes e conversar sobre o conhecimento do conteúdo e conhecimento pedagógico do conteúdo, narrados nos resultados das investigações.

Outro aspecto recorrente nas investigações que foram analisadas é o acolhimento pautado no diálogo e na aceitação das diferenças, advindas dos modos de pensar dos integrantes que participam do grupo, levando em consideração as diferenças culturais presentes na formação pessoal e profissional. As pesquisas mostraram que é possível desenvolver propostas de formação 
de professores inseridas em um caminho reflexivo que valida a singularidade do professor, atrelada à sua formação e ao seu modo de ser e pensar sobre a educação.

Ao conhecer sobre como essas redes foram se construindo, passamos a compreender que elas se entrelaçam pela colaboração e pelo desejo de estar com o outro. Na convivência, aprendem a valorizar o que fazem, a ensinar e compartilhar as descobertas e as novidades teóricas, e isso para construir propostas de estudos e trabalhos que se remodelem no fluxo do viver e conviver, nesses espaços de formação. A experiência, também, advém das atividades de leitura, que são permeadas pela reflexão e discutidas de forma não verticalizada nos espaços de formação.

Os coordenadores explicitam que os interesses de estudos são vários, e cada um deles ganha o seu momento no grupo para explorar, compartilhar e refletir sobre determinado assunto e autor. Aduzem que as realidades são agregadas aos temas a serem estudados, como uma aventura que possui um roteiro, porém não é fixado nem planejado de modo técnico, mas com possibilidades de que a experiência da leitura aconteça. A experiência, ao contrário do experimento, não pode ser planejada de modo técnico. A atividade da leitura é, às vezes, experiência e, às vezes, não. Porque ainda que a atividade da leitura seja algo que fazemos regular e rotineiramente, a experiência da leitura é um acontecimento que tem lugar em raras ocasiões.

Como afirma Larrosa (2011) [12], o acontecimento da experiência produz-se em certas condições de possibilidade, mas não se subordina ao possível. Os encontros, de acordo com coordenadores 1 e 2, seguem o curso da pluralidade e da incerteza, são desprovidos da causalidade técnica, que reduz o espaço em que a experiência pode produzir-se como acontecimento. Para o Larrosa (2011, p.14) [12] "isto é, convertê-la em experimento, em uma parte definida e sequenciada de um método ou de um caminho seguro e assegurado para um modelo prescritivo de formação".

O conversar dos coordenadores indica-nos que o modelo prescritivo é rompido nos grupos investigados porque as discussões teóricas, geralmente, são mediadas por um integrante do grupo e, com isso, a aproximação entre os pares e, consequentemente, entre a universidade e a escola acontece respeitando essas condições de possibilidades afirmadas por Larrosa (2015) [6], que são confluentes com o texto, o momento e a sensibilidade, no sentido favorável para que cada integrante possa ser (ou não) lugar para o acontecimento da experiência. Essa característica presente nos grupos de estudos e pesquisas demarca a importância deles para a formação de professores, pois, quando o modelo pautado na convocação e na prescrição é rompido, abre espaço para a experiência de um trabalho pautado no acolhimento, diálogo, respeito e colaboração entre os pares.

As narrativas reafirmaram a importância de agregar os professores das escolas para, a partir das discussões que emergem dos encontros, compreender e produzir sentidos para as ações na docência e na profissionalização dos envolvidos. Essas relações, que acontecem em rede, emergiram recursivamente e mostraram-se pelo emocionar e pelo linguajar da colaboração e da espontaneidade. Os interesses e as intencionalidades pessoais e profissionais entrecruzam-se pelas ações e temáticas que compõem os planejamentos dos grupos de estudos e pesquisas. Ao conhecer sobre como essa rede construiu-se, compreendemo-la entrelaçada por condutas que proliferam ações colaborativas, em que o querer estar presente no grupo potencializa as atividades demarcadas pela experiência de pesquisar, ensinar e compartilhar as descobertas e as novidades teóricas, para, assim, construir propostas de estudos e trabalhos que se remodelam no fluxo do viver e conviver nesses espaços de formação.

O sentido produzido pelas experiências contadas nas narrativas, referente à relação do trabalho realizado em cada grupo e as relações com as pesquisas geradas a partir desses encontros, está diretamente atrelado às práticas pautadas na colaboração. Os planos de trabalho são flexíveis para, dessa forma, acolherem as ideias e necessidades dos professores e futuros professores que se agregam aos grupos.

A reciprocidade e as parcerias de trabalho enlaçam-se à colaboração e são reafirmadas nas duas narrativas, enaltecendo os grupos de estudos e pesquisas como espaços que geram potencialidades na formação de professores. Ou seja, o fluxo de trabalho e a colaboração acontecem não somente pela extensão da universidade para com a escola, mas na reciprocidade que mostra o acolhimento das demandas que vão surgindo, atendendo a convites e solicitações feitas pela Coordenadoria de Educação. 
Compreendemos essas relações inseridas numa dinâmica que potencializa não somente a formação inicial e contínua, tanto dos professores da escola e como da formação inicial dos acadêmicos, mas a contínua formação e o fluxo que movem o aprender e o conhecer dos professores da universidade pela experiência e a reflexão da experiência.

Ao analisar as pesquisas encontradas nas diferentes bases de dados, percebemos que existem distinções que demarcam a originalidade da investigação por nós apresentada e, com isso, reconhecemos aspectos que contribuem e avançam nas pesquisas que tangem à formação de professores em grupos de estudos e pesquisas, são eles: o lócus de investigação, o critério de escolha dos grupos, o tempo que esses grupos estão ativos, os modos de planejamentos, o linguajar e o emocionar que permeiam as propostas dos grupos de estudos e pesquisas e o modo que esses encontros acontecem, tendo o conviver espontâneo como característica comum entre os grupos.

O estudo que realizamos mostrou que estamos diante de outra cultura de formação; e essa propõe espaços de convivências e momentos permeados pela cooperação e acolhimento, legitimação de si e do outro, respeito e diálogo, visualizamos interações mobilizadas pelo emocionar que preza por espaços saudáveis de formação e transformação dos sujeitos.

\section{CONCLUSÃO}

As experiências narradas contam sobre os espaços de formação inseridos num tempo que requer abrir possibilidades para um conversar no sentido de dar voltas com o outro, na convivência que possibilita compartilhar saberes, de forma espontânea, não deixando de atender às demandas prescritas pela legislação e pelas necessidades apontadas pelos programas de formação, mas promovendo encontros permeados por sentidos, coletivos e individuais, para as práticas docentes desenvolvidas nas escolas e na universidade e para cada integrante envolvido com a educação, na singularidade que o constitui.

A investigação muniu-nos de elementos para inferir que os grupos aderem a essa linha de trabalho, compreendida como possibilidade de tramar ações entre a escola e a universidade, pelo viés do acolhimento, integração, colaboração e atividades que visam compartilhar saberes, tendo o remodelamento e a inovação das práticas como dispositivos para produzir outros sentidos no ensino, na formação de professores e no construir formas de proliferar teorias e práticas para a educação contemporânea. Essa rede harmônica de relações entre os participantes vai reconfigurando-se devido à volatilidade que demarca a presença dos participantes, porém os grupos conservam-se e permanecem ativos.

Pela pesquisa, foi possível compreender que os grupos de estudos e pesquisas analisados abrem espaços para as ações de colaboração pelas vias do ensino, da pesquisa e da extensão, de forma a acolher, integrar, compartilhar e produzir outros conhecimentos científicos, na experiência, que é singular, e no coletivo dessa convivência.

$\mathrm{O}$ estudo avança de outras pesquisas analisadas porque indica o que os mantêm ativos por mais tempo, que é a espontaneidade do encontro, além de outros elementos que foram capturados pelas narrativas, como a reestruturação e o fluxo de interesses de estudos e atividades pedagógicas advindas dos integrantes do grupo, mostrando acolhimento, legitimação e reconfiguração contínua das ações do grupo. Podemos inferir que outra cultura de grupo configura-se com uma identidade que constitui os professores pela formação não imposta, mas compartilhada no sentido de dialogar e refletir em redes de conversação.

Compreender o emocionar que pauta as relações em rede, que transitam pela cultura do acolhimento, respeito e legitimação do outro, remete-nos a pensar e propor outras propostas para encontros de formação de professores, em que o viver e o conhecer entrelacem-se e transformem os integrantes na convivência. $\mathrm{O}$ emocionar de respeito e legitimação promove os encontros dos grupos de estudos e pesquisas investigados, por conseguinte, evidenciando a possibilidade do acontecimento da experiência, o que perpassa as rotinas rígidas de formações de professores, muitas vezes, presentes nesses processos, dessa forma, proporcionando que as conversações sejam de participação, inclusão, colaboração, compreensão, acordo, respeito e conspiração. 
A legitimação do outro e o acolhimento constituem-se no elo entre a universidade e a escola e derivam da legitimação e do comprometimento de quem lidera, ou seja, da pessoa do coordenador e dos seus respectivos colaboradores. Entretanto, no caminhar conjunto, os integrantes dos grupos desenvolvem-se como membros de uma cultura que cresce em redes de conversação, em contínua transformação consensual de condutas e, por que não, de condutas docentes.

A investigação proliferou reflexões e resultados pertinentes à formação de professores em grupos de estudos e pesquisas que poderão embasar propostas futuras nesses espaços que integram os professores da universidade, da escola e acadêmicos dos cursos de licenciatura, e isso no sentido de afirmarmos que a experiência é, sempre, singular, do mesmo modo, que a experiência que ocupa o lugar na vida de cada integrante dos grupos de estudos e pesquisas investigados é, sempre, subjetiva, pois somos sujeitos capazes de deixar que algo passe-nos, que passe as nossas palavras, ideias e sentimentos. É a abertura do próprio sujeito que remete ao sensível, vulnerável e exposto. Enfim, o sujeito aberto à sua própria transformação é o sujeito que, quando na convivência espontânea nos grupos, faz a experiência acontecer e, em sua subjetividade, faz da experiência sua própria transformação.

Grupos de estudos e pesquisas que promovem encontros de formação de professores, de modo que os sujeitos se reúnam na espontaneidade para conviver e dar voltas com o outro e com a possibilidade da reflexão, têm-se mostrado potentes para a continuidade do processo de formação docente. Com o outro é possível conhecer o próprio conhecer, não a partir do conhecimento do outro, mas do encontro com o próprio conhecer. Realizar o estudo com esses grupos nos mostrou que estamos na direção de trabalhos coletivos em que as propostas de estudo, pesquisas e formações serão pautadas e construídas em espaços de convivência constituídos no emocionar em que os seres possam se transformar espontaneamente ao conviver com o outro.

\section{REFERÊNCIAS BIBLIOGRÁFICAS}

1. Bagé. Unipampa. Plano de Desenvolvimento Institucional (2014 -2018). Bagé, RS: [s.n.]; 2013. [acesso 2016 dez.]. Disponível em: http://porteiras.unipampa.edu.br

2. Marchi VD. Um grupo de estudos de professores de matemática e a exploração de conteúdos de Geometria Euclidiana em Webquest. Dissertação. São Paulo: Universidade Anhanguera de São Paulo; 2011.

3. Orfao RB. Professores de matemática em um grupo de estudos: uma investigação sobre o uso da tecnologia no ensino de funções trigonométricas. Dissertação. São Paulo: Universidade Anhanguera de São Paulo; 2012.

4. Loponte LG. Amizades: o doce sabor da docência. Cadernos de Pesquisa, São Paulo 2009 Set/Dez;39(138):919-38. [acesso 2017 jun. 20]. Disponível em: http://www.scielo.br/scielo.php?script=sci_arttext\&pid=S0100-15742009000300012.

5. Gabardo CV, Hagemeyer RC. Formação docente continuada na relação universidade e escola: construção de referências para uma análise a partir da experiência do PDE/PR. Educar em Revista 2010 Mai/Ago;(37):93-112. [acesso 2017 jun. 10]. Disponível em: http://www.scielo.br/scielo.php?script=sci_arttext\&pid=S0104-40602010000200007.

6. Larossa J. Tremores: escritos sobre a experiência. Belo Horizonte: Autêntica; 2015.

7. Maturana H. Emoções e linguagem na educação e na política. $3^{\text {a }}$ ed. Belo Horizonte: UFMG; 2009.

8. Maturana H. A ontologia da realidade. $2^{a}$ ed. Belo Horizonte: UFMG; 2014.

9. Maturana H. Cognição, ciência e vida cotidiana. Tradução: Cristina Magro e Victor Paredes. Belo Horizonte: UFMG; 2001.

10. Galvão C. Narrativas em Educação. Revista Ciência \& Educação 2005 Mai/Ago;11(2).

11. Connelly M, Clandinin J. Pesquisa narrativa: experiências e história na pesquisa. $2^{\mathrm{a}}$ ed. Uberlândia: EDUFU; 2015.

12. Larrosa J. Experiência e alteridade em educação. Revista Reflexão e Ação 2011 Jul/Dez;19(2):04-27.

13. Larrosa J. Tecnologias do eu e educação. In: Silva T. O sujeito da educação. Petrópolis: Vozes; 1994. p.3586.

14. Maturana HR, Varela FJ. A árvore do conhecimento: as bases biológicas da compreensão humana. $9^{\mathrm{a}}$ ed. São Paulo: Palas Athena; 2011. 
15. Larrosa, J. Notas sobre a experiência e o saber de experiência. Rev. Bras. Educ. [online]. 2002(19):208. ISSN 1413-2478. [acesso 2018 jan. 20]. Disponível em: http://dx.doi.org/10.1590/S141324782002000100003 . 